\title{
Wnt Positive
}

National Cancer Institute

\section{Source}

National Cancer Institute. Wht Positive. NCI Thesaurus. Code C129451.

Indicates that expression of one or more Wnt family members has been detected in a sample. 